\title{
A Novel Design of Cooling Air Supply System with Dual Row Pre-Swirl Nozzles
}

\author{
Z. L. Xia ${ }^{1}$, S. F. Wang ${ }^{1 \dagger}$ and J. C. Zhang ${ }^{2}$ \\ ${ }^{1}$ Nanjing University of Aeronautics and Astronautics, Aero-engine Thermal Environment and Structure Key \\ Laboratory of Ministry of Industry and Information Technology, Nanjing, Jiangsu, 210016, China \\ ${ }^{2}$ Aero Engine Academy of China, Beijing, 101304, China \\ †Corresponding Author Email: sfwang@nuaa.edu.cn
}

(Received September 9, 2019; accepted December 18, 2019)

\begin{abstract}
A novel design of cooling air supply system with dual row pre-swirl nozzles (DRPM) is promoted and investigated. Simplified theoretical analysis and numerical simulation are used to estimate the total temperature reduction and mass flow rate characteristic of DRPM and compared with single row pre-swirl nozzle model (SRPM). The results show that, both models have similar flow structure and the variation of total temperature reduction and dimensionless mass flow rate with rotational Reynolds number and pressure ratio is also similar. Which have an inflection point with the increase of rotational Reynolds number but increases monotonically with the variation of pressure ratio. The pre-swirl system has the maximum flow rate and temperature reduction when the inflow Angle equal to 0 or the swirl ratio equal to 1 at the inlet of the receiver hole. The increase in pressure ratio improves the total temperature reduction and dimensionless mass flow rate as well. In the range of rotational Reynolds number calculated, DRPM can increase the dimensionless mass flow rate by $3.0 \%$ but the total temperature reduction decreased by $37.8 \%$ in average compared with SRPM. On the other hand, the dimensionless mass flow rate increased by $2.8 \%$ and total temperature reduction decreased by $14.9 \%$ in average in the range of pressure ratio calculated. Numerical results are in good agreement with the results calculated by simplified theoretical formulas.
\end{abstract}

Keywords: Dual row pre-swirl nozzle; Axial pre-swirl system; Total temperature reduction; Swirl ratio; Rotor-stator cavity; Rotational Reynolds number; Pressure ratio; Dimensionless mass flow rate.

\section{NOMENCLATURE}

$a$

A

b

(charge coefficient

$c_{p} \quad$ specific heat capacity

$C_{W}$ dimensionless mass flow rate

d diameter

M momentum

$m$ mass flow rate

$P \quad$ pressure

$P^{*} \quad$ total pressure

$r$ radius

$R e_{\omega} \quad$ rotational Reynolds number

$T^{*} \quad$ total temperature

$V \quad$ velocity

$V_{\phi} \quad$ tangential velocity in the stationary frame

$\Delta T^{*}$ $\alpha \quad$ flow incidence angle

$\beta \quad$ swirl ratio

$\Theta \quad$ total temperature reduction coefficient

$\mu \quad$ dynamic viscosity

$\rho \quad$ density

$\omega \quad$ angular velocity of the disk

$\delta \quad$ flow distribution ratio

subscript

dual refers to DRPM

in system inlet

$p 1 \quad$ the upper pre-swirl nozzle of DRPM

p2 the lower pre-swirl nozzle of DRPM

$r \quad$ rotational disk

rel relative to the rotational disk

rh receiver hole

single refers to SRPM 


\section{INTRODUCTION}

With the development of aeroengine design technology, the cycle parameters of the engine are constantly improved. The gas temperature in the mainstream channel is constantly rising. To ensure the safe and reliable operation of turbine blades and prevent damage caused by excessive temperature, effective cooling is needed. Cooling air from the high-pressure compressor is introduced into the turbine blade root through the pre-swirl system to cool the turbine blades. As an important part of the internal air system in aeroengine, the pre-swirl system provides high pressure and low total temperature coolant air. A typical axial pre-swirl system is presented in Fig. 1, cooling air enters the rotor-stator cavity through a row of pre-swirl nozzles established on the stator disk with a certain angle. Static temperature is reduced during the isentropic expansion progress in the pre-swirl nozzle, the direction of tangential velocity component is the same as the rotation direction of the disk at the outlet of the pre-swirl nozzle, thus reduce the relative velocity of cooling air in rotorstator cavity and at the inlet of the receiver hole, then the relative total temperature is reduced because of the decrease of relative velocity.

The pre-swirl system was first promoted in the 1970s, and many scholars have done a lot of works on this system using theoretical analysis, numerical simulation and experimental research methods. A large number of in-depth research results have been widely used in aeroengine and gas turbine design. Meierhofer and Franklin (1981) evaluated the total temperature reduction in a direct transfer pre-swirl system through experimental investigation using pre-swirl effectiveness, Popp et al. (1998) calculated the discharge coefficient and temperature reduction of the pre-swirl nozzle numerically, showed the importance of pre-swirl nozzle design in cooling system efficiency. Dittmann et al. (2002), Karabay et al. (2000), Karabay et al. (2001), and Bricaud et al. (2005) found the geometry of pre-swirl nozzle inlet and pressure ratio played a more important role in discharge coefficient rather than the geometry of rotor-stator cavity and the number of the pre-swirl nozzles. Chew et al. (2003) proved the discharge coefficient of the pre-swirl nozzle increases with the pressure ratio due to the compressibility of the pre-swirl nozzle. Lewis et al. (2009) evaluated the flow and heat transfer performance in a direct transfer system with a pre-swirl nozzle of different radial locations. The influence of rotating speed, mass flow rate, swirl ratio and pre-swirl nozzle number on the performance of pre-swirl system were carried out by Yan et al. (2003). Liao et al. (2014) presented numerical and experimental research on the influence of pre-swirl nozzle structure, pressure ratio and rotating speed on temperature reduction and total pressure drop. Wang et al. (2007) presented the influence of the radial location of the pre-swirl nozzle on the temperature reduction and heat transfer on the rotor disk surface. Furthermore, Zhang et al. (2015) investigated the effect of the length-to-diameter ratio of the pre-swirl nozzle on the performance of a direct-transfer pre-swirl system in a rotor-stator cavity and promoted the relationship between characteristics of pre-swirl nozzle outlet with length-to-diameter ratios and turbulent flow parameters.

Ciampoli et al. (2007) promoted a pre-swirl nozzle optimization with computational fluid dynamics (CFD) method. Javiya et al. (2011) compared the performance of the pre-swirl system with three kinds of pre-swirl structure with the same pre-swirl angle, the results showed the cascade vane type preswirl nozzle performed the best with largest discharge coefficient and highest temperature reduction. Furthermore, Liu et al. (2017) designed a new vane-shaped hole pre-swirl nozzle with better pre-swirl effectiveness but little advantage in the discharge coefficient. Sun and Chew (2017) designed a new concept pre-swirl system with cooling air with different temperatures supplied at different radius, evaluated the feeding effectiveness through CFD investigations.

It should be noted that most of the previous studies of the axial pre-swirl system were all about single row pre-swirl system (SRPM). Although pre-swirl nozzle with high radial location is adopted to obtain higher temperature reduction, the heat transfer at the lower radius is poor, a larger temperature gradient formed on the surface of the turbine disk which is harmful to the stability and safety of turbine components. Besides, the cycle parameters of the aeroengine vary greatly in different operating states such as take-off, cruise, and maneuver, and the requirements for the pre-swirl system are not the same. A pre-swirl system with single row pre-swirl nozzles will cause a waste of cooling air. In this paper, a dual row pre-swirl model (DRPM) is promoted. The effects of rotational Reynolds number and pressure ratio on the performance of DRPM were reported numerically and compared with SRPM. The research results in this paper can provide technical guidance for the exploration of a new type of adjustable pre-swirl system, which is of great significance in the design of efficient aeroengine internal air system.

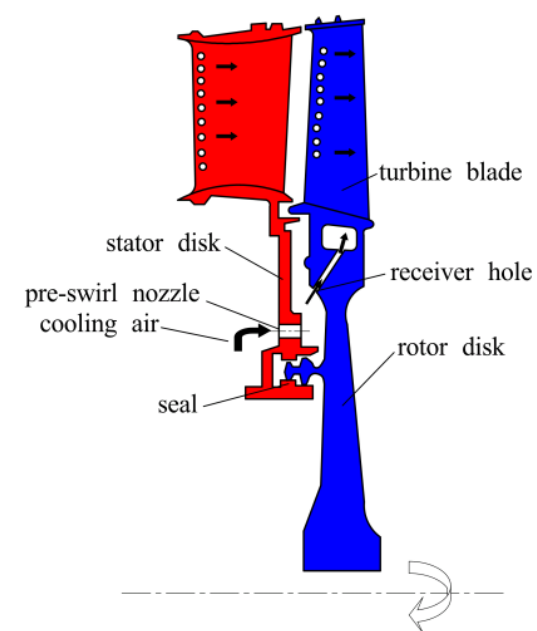

Fig. 1. Schematic of a typical axial pre-swirl system. 


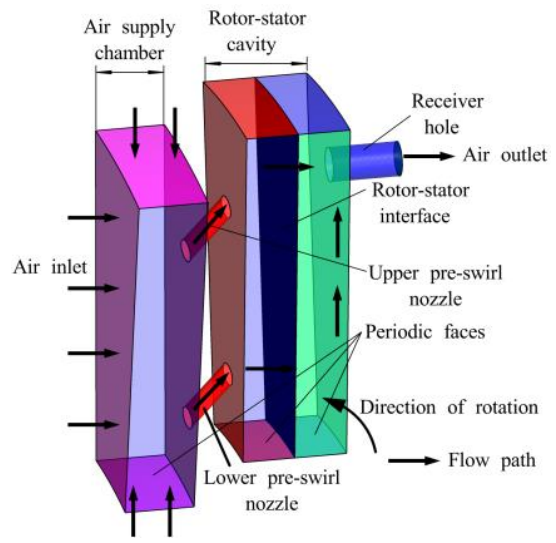

(a) 3-D view of DRPM

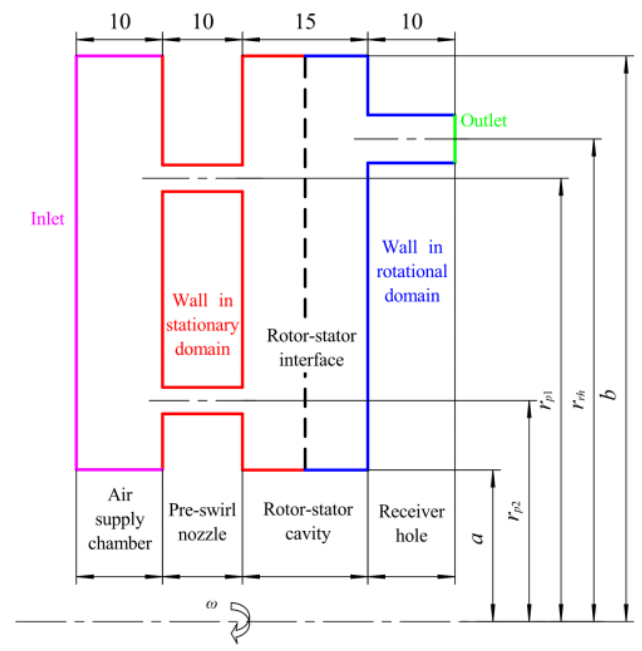

(c) 2-D axial symmetric view of SRPM

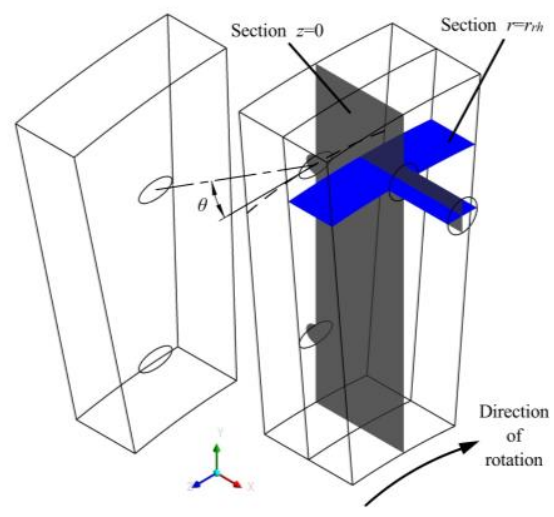

(b) schematic of the pre-swirl angle and sections used

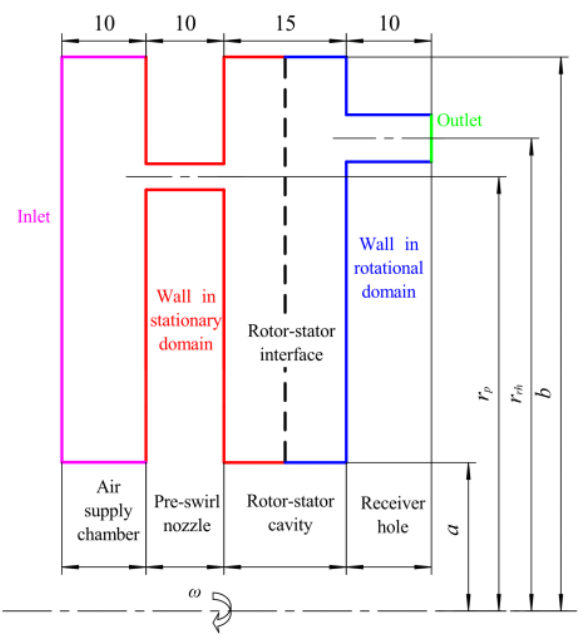

(d) 2-D axial symmetric view of DRPM

Fig. 2. Schematic of the computational model.

\section{MODEL AND COMPUTATIONAL METHODS}

\subsection{Computational Model and Mesh Generation}

As shown in Fig. 1, a typical axial pre-swirl system consist of rotor and stator, which lead to a seal problem, the upper seal structure is designed to prevent gas ingression, and the lower seal is designed to prevent coolant leakage. Both seal structure may have a small quantitative effect on the performance of the pre-swirl system but doesn't affect the overall evolution. So the seal structures are ignored in the computational model. Besides, the complex surface cavity was simplified into a rectangular cavity and the conclusions obtained can be applied to the complex surface cavity with some modifications.

A schematic of the computational model is shown in Fig. 2. The computational domain consists of an air supply chamber, pre-swirl nozzle, rotor-stator cavity, and receiver hole. The air is bled from the upstream air supply chamber which is shown in Fig. 2(a) as pink faces and bold pink lines in Figs. 2(c) and (d). Cooling air enters the rotor-stator cavity after expanded and accelerated in pre-swirl nozzles which are uniformly arranged on the stationary disk along the circumferential direction. Air flows out through the equal spaced receiver holes on the rotor disk. The computational domain for all the models is a three-dimensional sector which contains one pre-swirl nozzle in each row and one receiver hole. The stationary domain contains an air supply chamber, pre-swirl nozzle and half of the rotorstator cavity, the walls of the stationary domain are shown in Fig. 2(a) as red faces and bold red lines in Figs. 2(c) and (d). The other half of the cavity and the receiver hole constitute the rotational domain and the walls of which is shown in Fig. 2(a) as blue faces and bold blue lines in Figs. 2(c) and (d). The stationary domain and rotational domain are connected by a rotor-stator interface in the middle of the rotor-stator cavity, which is marked in Fig. 2(a) with a darker color and bold black dotted line in Figs. 2(c) and (d).

The pre-swirl angle is defined as the angle between the nozzle axis and the tangent direction of the rotating disk, which is fixed at $30^{\circ}$ for each preswirl nozzle in this paper. Figure 2(b) shows the 
definition of pre-swirl and the locations of the meridian section $(z=0)$ and circumferential section near the receiver hole $\left(r=r_{r h}\right)$ used in Figs. 3, 4 and 5 . The outer radius of the rotor-stator cavity $b$ is 150 $\mathrm{mm}$, while the inner radius is $a$. The radial location of the pre-swirl nozzle is $r_{p 1}$ and $r_{p 2}$ while the diameter is $d_{p 1}$ and $d_{p 2}$, the relations among the geometry parameters are: $a / b=0.667, r_{r h} / b=0.933$, $r_{p} / b=r_{p 1} / b=0.9, r_{p 2} / b=0.733, A_{p 1}=A_{p 2}=0.5 A_{p}$, where $A=\frac{1}{4} \pi d^{2}$ denotes the flow area of the pre-swirl nozzle.

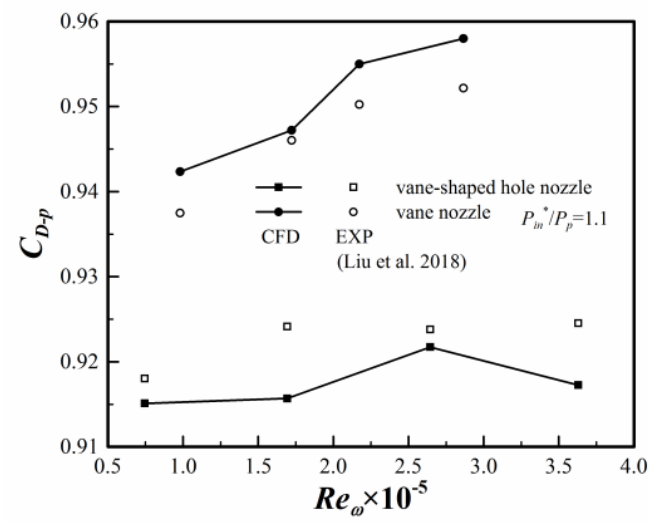

Fig. 3. Comparison of numerical results with experimental data.

The software package CFX 15.0 with mesh generator ICEM has been used throughout the study. To reduce the mesh generation time, the tetrahedral unstructured mesh was employed. According to the description in ANSYS CFXSolver theory guide by ANSYS, Inc. (2013), mesh inflation was set near all the walls to ensure that the first layer of mesh is located outside the viscous sublayer, in the buffer layer or the logarithmic layer of complete turbulent state and the range of $y^{+}$on the walls is between 30 and 150 within all the calculation cases which meet the requirements of scalable wall function for boundary layer meshes near the walls. Mesh independence validation with five sets of mesh numbers is considered in SRPM: 240000 cells, 470000 elements, 680000 elements, 930000 elements, and 1050000 elements. The results show that the maximum difference in the total temperature reduction is within $1.2 \%$ when the element number is more than 680000 . Thus the mesh with 680000 elements in SRPM and about 880000 elements in DRPM is employed for numerical simulations.

\subsection{Computational Methods Boundary Conditions} and

According to the conclusion drawn by Liu et al. (2017), Liu et al. (2018), and Wu et al. (2011), a reasonable match between numerical and experimental results using different turbulence models can be proved. Numerical results using the computational model in Liu et al. (2018) together with mesh generation and computational methods in this paper were compared with experimental results presented. As can be seen in Fig. 3, for all the rotational Reynolds numbers simulated, the average $C_{D}$ error in numerical simulation is about $1.1 \%$. Finally, the standard $k-\varepsilon$ turbulence model with scalable wall function was chosen based on Fig. 3 and the author's previous work experience on preswirl system research.

The high-resolution option is chosen for both the advection scheme and turbulence modeling to obtain more accurate and reliable results, which is widely used in related research. Conservation is achieved when all the residuals are less than $1 \times 10^{-5}$ and the physical quantities on the monitoring surface are stable and basically unchanged. The fluid domains are set using MRF (multiple frames of reference) method which allows the analysis of the situations involving domains that are rotating relative to one another and is quite common in the investigation of rotor/stator interaction for rotating machinery. According to the conclusion drawn by Benim et al. (2005) and Wu et al. (2011), the spatial variations of the variables are transmitted across the interface boundary, without any averaging, for a given relative position of the stator and rotor in frozen rotor approach, which can deliver similar results to the unsteady analysis. So, the "frozen rotor" approach was applied to the rotor-stator interface in this study. For more details, please refer to the ANSYS CFX-Solver theory guide file (ANSYS, Inc. 2013)

All the models are calculated under the same conditions. The air density is calculated by the ideal gas law. The pressure boundary condition is applied to both inlet and outlet locations. Total pressure at the inlet is fixed to $0.7 \mathrm{MPa}$ with a uniform $700 \mathrm{~K}$ total temperature. The outlet static pressure is determined based on the system pressure ratio. The rotation axis and angular speed are set to the rotational fluid domain. All the periodic faces in the air inlet chamber and rotor-stator cavity are set to be rotational periodic interface and the axis is the same with the rotational fluid domain.

All the walls or the solid parts in the axial pre-swirl system are made of alloy materials and there is a complex heat transfer between fluid and solids, which make the flow and heat transfer characteristics in an axial pre-swirl system complex and hard to predict and explain. The heat transfer between the wall and fluid may have a small quantitative effect on the performance of the preswirl system but doesn't affect the overall evolution especially when we focus on the total temperature reduction and mass flow rate characteristics difference caused by variation of pre-swirl nozzle geometry. So all the walls are set to be adiabatic, no-slip and stationary relative to their own domain.

\subsection{Parameter Definition}

For pre-swirl system, five critical parameters are used to estimate its performance: the rotational Reynolds number $\left(\operatorname{Re}_{\omega}\right)$, (Chew et al. 2003), the dimensionless mass flow rate $\left(C_{W}\right)$, (Farzaneh-Gord et al. 2005) the total temperature reduction 
coefficient $(\Theta)$, (Farzaneh-Gord et al. 2005), the discharge coefficient $\left(C_{D}\right)$, (Dittmann et al. 2002), and the swirl ratio $(\beta)$, (Lewis et al. 2008). The definition of these parameters are as follow:

$R e_{\omega}=\rho \omega b^{2} / \mu$

Where $\rho$ is the density of air, $\omega$ is the rotational angular velocity, $\mu$ denotes the air dynamic viscosity and $b$ is the rotor-stator outer radius. Rotational Reynolds number is used to dimensionless the angular velocity and defined as the ratio of inertial force and viscous force.

$$
C_{W}=m / \mu b
$$

Where $m$ denotes the mass flow rate.

$$
\Theta=\frac{2 c_{p} \Delta T^{*}}{\left(\omega r_{r h}\right)^{2}}=\frac{2 c_{p}\left(T_{i n}^{*}-T_{r h, r e l}^{*}\right)}{\left(\omega r_{r h}\right)^{2}}
$$

Where $c_{p}$ is the specific heat capacity, $T^{*}$ denotes total temperature, subscript $r h$ represents the receiver hole.

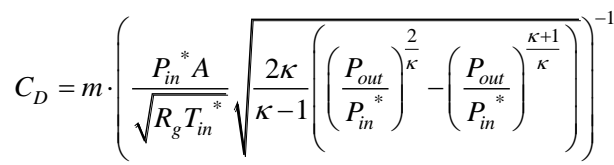

Where $P^{*}$ represents total pressure and $P$ represents static pressure, $R_{g}$ is the gas constant, $\kappa$ is the isentropic exponent. It should be noted that the relative value of inlet total pressure and temperature should be used when calculating the discharge coefficient of the rotational receiver hole.

$$
\beta=V_{\phi} / \omega r
$$

Where $V_{\phi}$ is the tangential component of absolute velocity vector and $r$ denotes radius.

\section{TheORETICAL ANALYSIS}

In the dual row axial pre-swirl system, the energy conservation law can be written as:

$$
\sum_{i=1}^{2} \dot{m}_{p i} c_{p}\left(T_{r h}^{*}-T_{p i}^{*}\right)=-M_{r} \omega
$$

In the rotor-stator cavity, tangential momentum conservation equation can be written as:

$$
\begin{aligned}
M_{r}+M_{s}= & \sum_{i=1}^{2} m_{p i} r_{p i} V_{p i, \phi} \\
& -r_{r h} V_{r h, \phi}\left(m_{p 1}+m_{p 2}\right)
\end{aligned}
$$

Define the flow distribution ratio as:

$$
\delta_{p i}=m_{p i} /\left(m_{p 1}+m_{p 2}\right)
$$

The relationship between total temperature in the rotational frame and stationary frame in receiver hole can be expressed as:
$c_{p}\left(T_{r h}{ }^{*}-T_{r h, r e l}{ }^{*}\right)=\frac{1}{2} V_{\phi, r h}{ }^{2}$

Eq. (9) can be simplified combined with Eq. (6) to Eq. (8):

$$
\begin{aligned}
c_{p}\left(T_{p}^{*}-T_{r h, r e l}{ }^{*}\right)= & \frac{1}{2} V_{r h, \phi}{ }^{2}-r_{r h} V_{r h, \phi} \omega \\
& +\omega \sum_{i=1}^{2} \delta_{i} r_{p i} V_{p i, \phi} \\
& -\frac{M_{s} \omega}{m}
\end{aligned}
$$

Using the definition of total temperature reduction coefficient and swirl ratio, Eq. (10) can be rewritten as:

$$
\begin{aligned}
\Theta= & \beta_{r h}^{2}-2 \beta_{r h} \\
& +2 \sum_{i=1}^{2}\left[\delta_{i} \beta_{p i}\left(\frac{r_{p i}}{r_{r h}}\right)^{2}\right] \\
& -\frac{M_{s}}{0.5 m \omega r_{r h}{ }^{2}}
\end{aligned}
$$

Considering the ideal condition, the circumferential velocity of airflow at the receiver hole is equal to the rotational velocity of the disk, then $\beta_{r h}=1$ and the friction torque on the surface of the stator is ignored. Equation (11) can be simplified as:

$$
\Theta_{\text {dual }}=2 \sum_{i=1}^{2} \delta_{i} \beta_{p i}\left(\frac{r_{p i}}{r_{r h}}\right)^{2}-1
$$

The total temperature reduction coefficient in SRPM was derived by Lewis et.al (2008) with the ignition of friction torque on the surface of the stator as:

$\Theta_{\text {single }}=2 S r_{p}\left(\frac{r_{p}}{r_{r h}}\right)^{2}-1$

Compare Eq.(12) and Eq.(13), a similar form can be found. The main parameters that affect the total temperature reduction coefficient of DRPM include the swirl ratio and flow distribution ratio at the outlet of the pre-swirl nozzle, relative position of the pre-swirl nozzle and the receiver hole and the swirl ratio at receiver hole. The effects of these parameters will be discussed in detail below.

\section{AnAlysis Of ReSUlts}

\subsection{Flow Characteristics}

The streamline and dimensionless pressure $P / P_{i n}{ }^{*}$ in the $z=0$ plane are shown in Fig. 4. with $R e_{\omega}=2.15 \times 10^{6}$ and $P_{\text {in }}{ }^{*} / P_{\text {out }}=1.4$. In the SRPM, air enters the rotor-stator cavity from single row preswirl nozzle and divides into three paths: the first part of air impacts the rotational wall and then moves outward, forming a counterclockwise vortex, occupies the outer part of the cavity; the second and main part of the flow flows axially through the 
rotor-stator cavity into the receiver hole; the third part of flow impacts the rotational wall, moves inward, forming a clockwise vortex at a lower radius than pre-swirl nozzle. This part of flow flows radial inward after reaching the stationary wall axially and forming a larger counterclockwise vortex due to the limitation of the inner radius wall, this counterclockwise vortex squeeze the clockwise vortexes formed by the second part flow in turn.

In DRPM, the streamline above the upper pre-swirl nozzle is similar to that of SRPM, part of the upper nozzle flow flows directly into the receiver hole at the same time. But the clockwise vortex below the upper nozzle disappears completely. Airflow from the lower pre-swirl impacts the rotational disk directly and forming a couple of reverse vortexes. The counterclockwise vortex formed by the lower pre-swirl nozzle and the clockwise vortex formed by the upper pre-swirl nozzle interact with each other, resulting in the disappearance of the clockwise vortex of the upper nozzle.

It can be found from the dimensionless pressure distribution contour that pressure increases with the increase of radius due to centrifugal supercharging effect (Lakshminarayana 1995), which means that the fluid pressure increases under the effect of centrifugal force when the fluid is flowing from low radius to high radius in a rotating system. But half of the fluid accelerates in the lower pre-swirl nozzle, causing a decrease of pressure in DRPM, but increases much faster than SRPM. The two models have the same pressure level at the inlet of the receiver hole.

Figure 5 shows the swirl ratio distribution contour in the $z=0$ plane. As shown in Fig. 4, the lower preswirl outlet has lower pressure and thus larger pressure ratio with higher velocity and which results in a larger swirl ratio. It can be read from the contour that the swirl ratio near the lower radius pre-swirl nozzle outlet is about 1.8 while only 0.8 at the same location in SRPM. On the other hand, the swirl ratio of the upper nozzle is slightly lower in DRPM compared with the same location in SRPM due to higher friction loss in half area pre-swirl nozzle. But the swirl ratio distributions near the receiver hole of both models are basically the same.

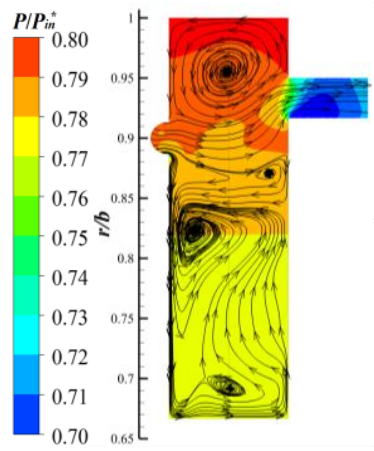

(a) SRPM

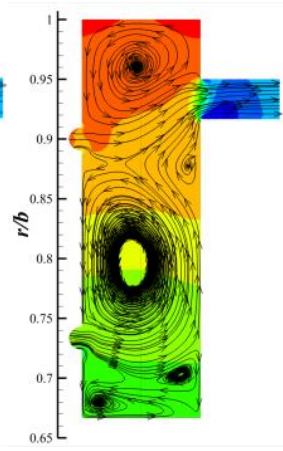

(b) DRPM
Fig. 4. Distribution of streamline and dimensionless pressure in the $z=0$ plane $\left(\operatorname{Re}_{\omega}=2.15 \times 10^{6} P_{\text {in }}{ }^{*} / P_{\text {out }}=1.4\right)$.

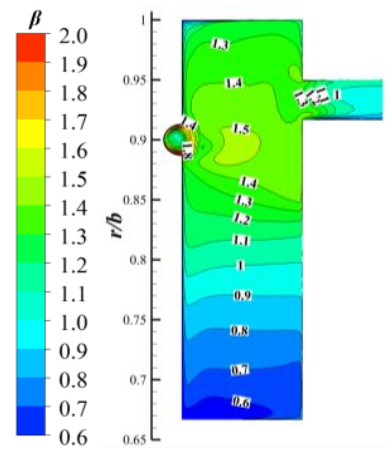

(a) SRPM

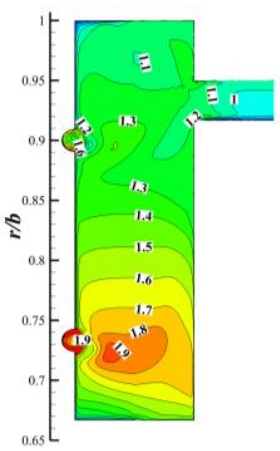

(b) DRPM
Fig. 5. Distribution of $\beta$ in the $z=0$ plane $\left(\operatorname{Re}_{\omega}=2.15 \times 10^{6} P_{\text {in }}{ }^{*} / P_{\text {out }}\right)$.

Streamlines in the tangential plane at the receiver hole radius $r=r_{r h}$ in a frame of reference rotating at the speed of the rotor (in the bottom to top direction) under different rotational Reynolds numbers are presented in Fig. 6. In each image, the stator is at the left but not shown and the receiver hole and the outlet is at the top. It can be seen that with the increase of the rotational Reynolds number, the way of flow entering the receiver hole gradually changes. Define the flow incidence angle $\alpha$ as the included angle between the direction of airflow entering the receiver hole and the axis of the receiver hole.

When the rotational Reynolds number is small, the fluid rotates faster than the receiver hole, and the airflow enters the receiver hole in the direction of rotation at a positive incidence angle, separating at the trailing edge wall of the receiver hole and causing a recirculation inside the receiver hole. With the increase of the rotational Reynolds number, the area of recirculation gradually decreases, and the flow incidence angle decreases. When the rotational Reynolds number reaches a certain value, the flow enters the receiver hole in an almost axial direction, and the flow incidence angle is close to 0 . It can be considered that the flow rotates approximately synchronously with the receiver hole. When the rotational Reynolds number continues to increase, the airflow rotated slower than the receiver hole, flow enters the receiver hole from the opposite direction of rotation at a negative angle and the flow separation occurs again but at the leading edge wall of the receiver hole. It can be found that the flow incidence angle achieves zero at a lower rotational Reynolds number in DRPM (between $2.15 \times 10^{6} \sim 3.0 \times 10^{6}$ ) compared to the SRPM (about $3.0 \times 10^{6}$ ). The flow resistance is the minimum and mass flow reaches the maximum at this point.

For a clearer comparison of components performance in both models, Table 1 shows the mass flow and temperature reduction parameters in both models. It can be seen from the table that, compared with SRPM, the discharge coefficients of the pre-swirl nozzle in DRPM are slightly larger than that in SRPM. The upper nozzle increased by about $0.45 \%$ while the lower nozzle increased by about $4.76 \%$. Besides, the dimensionless mass flow 

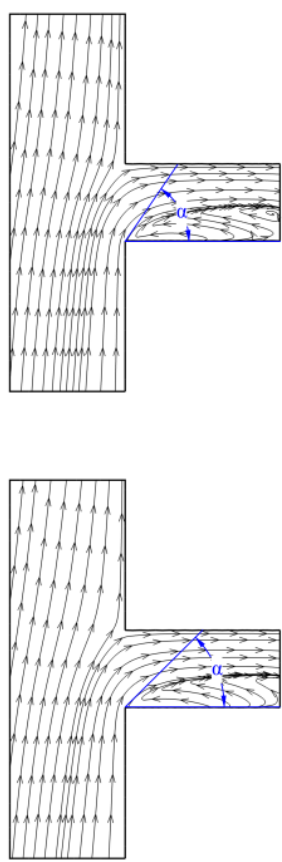

$R e_{\omega}=4.3 \times 10^{5}$
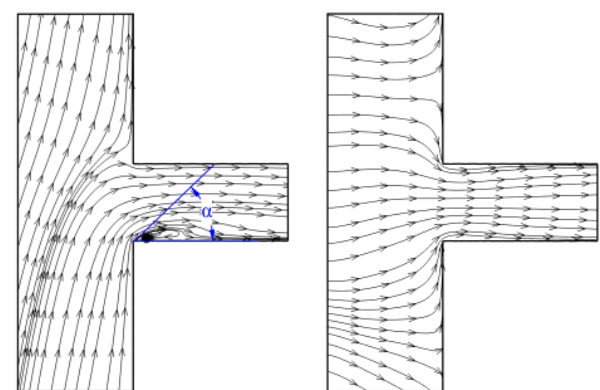

(a) SRPM
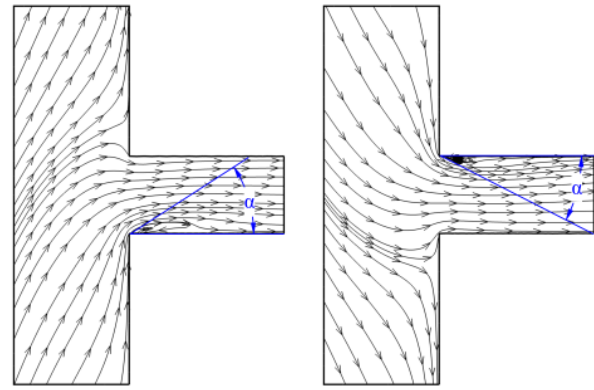

(b) DRPM
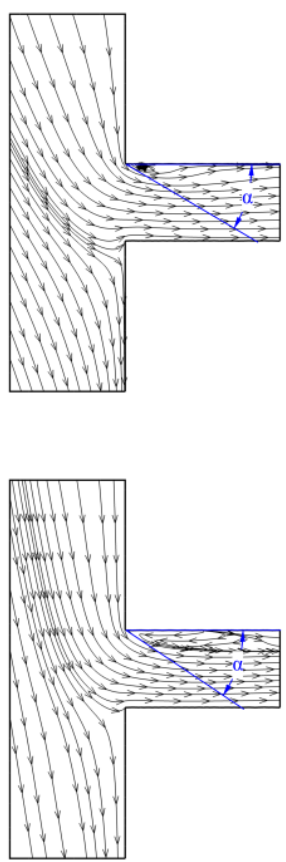

$R e_{\omega}=3.65 \times 10^{6}$

Fig. 6. Streamlines in the tangential plane at the receiver hole radius $(r / b=0.933)$, in a frame of reference rotating with the rotor (direction of rotation from bottom to top).

Table 1 Flow and temperature reduction parameters of single and dual row pre-swirl models

\begin{tabular}{|c|c|c|c|}
\hline \multirow{2}{*}{ Parameter } & \multirow{2}{*}{ SRPM } & \multicolumn{2}{|c|}{ DRPM } \\
\cline { 3 - 4 } & & $r_{p 1}$ & $r_{p 2}$ \\
\hline$C_{D-p}$ & 0.696938 & 0.700082 & 0.702574 \\
\hline$C_{D-r h}$ & 0.728401 & \multicolumn{2}{|c|}{0.78886} \\
\hline$C_{W}$ & 55425.84 & 27874.62 & 29151.08 \\
\hline$\beta$ & 1.626 & 1.566 & 1.686 \\
\hline${\text { flow } \text { angle/ }^{\circ}}^{\circ}$ & 26.037 & 26.96 & 26.868 \\
\hline$\Theta$ & 1.913 & \multicolumn{2}{|c|}{1.535} \\
\hline
\end{tabular}

rate of the lower nozzle is $4.58 \%$ higher than that of the upper nozzle while the total mass flow increases by about $2.89 \%$ compared with SRPM. The swirl ratio of lower radius pre-swirl nozzle increases by about $7.66 \%$ due to the smaller radius. The flow angles at the outlet of the pre-swirl nozzle in DRPM are larger and more close to the real pre-swirl angle $\left(30^{\circ}\right)$ due to a smaller nozzle diameter and the flow direction is more consistent with the nozzle axis. The total temperature reduction coefficient of DRPM is about $19.6 \%$ lower than the SRPM.

As analyzed in section 3 , the total temperature reduction coefficient is closely related to the swirl ratio of the pre-swirl nozzle and the receiver hole. Variation of swirl ratio with rotational Reynolds number and pressure ratio is presented in Fig. 7. The swirl ratio of all the pre-swirl nozzles decreases with the increases of rotational Reynolds number because of the increases of local disk rotational velocity but increases with system pressure ratio due to the more complete expansion progress in the pre-swirl nozzle and larger velocity at the pre-swirl nozzle outlet.

The swirl ratio at the inlet of the receiver hole is mainly affected by the flow incidence angle, which decreases with the rotational Reynolds number and gradually becomes negative. The swirl ratio of the receiver hole in DRPM achieves 1 at a lower rotational Reynolds number which was verified in Fig. 6. The swirl ratio at the inlet of the receiver hole increases with system pressure ratio, and larger than uniform when the pressure ratio is larger than 1.4. The swirl ratio of the pre-swirl nozzle in SRPM is between the upper and lower pre-swirl nozzle in DRPM but the swirl ratio of the SRPM receiver hole is always larger than that in DRPM.

\subsection{Mass Flow Characteristics}

Variation of $C_{W}$ with rotational Reynolds number and system pressure ratio is presented in Fig. 7. In Fig. 7 (a) $P_{\text {in }}{ }^{*} / P_{\text {out }}=1.4$ and keep constant. With the increase of rotational Reynolds number, the rotation speed of the disk increases, and the flow incidence angle of the airflow at the inlet of the receiver hole 
decreases gradually, increase the effective flow area and the mass flow rate increases. When the rotational Reynolds number continues to increase, the effective flow area decreases and the flow rate decreases as well. The position where the maximum flow value appears in Fig. 7(a) corresponds to the position where the swirl ratio at the inlet of the receiver hole is equal to 1 in Fig. 6(a). As a form of pressure differential driven flow, the dimensionless mass flow rate increases with the increase of system pressure ratio. As explained in section 4.1, dimensionless mass flow rate of DRPM is always larger than that in SRPM with the variation of $R e_{\omega}$ and $P_{\text {in }}{ }^{*} / P_{\text {out }}$, the maximum difference with $R e_{\omega}$ is about $3.0 \%$ and $2.8 \%$ with $P_{\text {in }}{ }^{*} / P_{\text {out }}$.

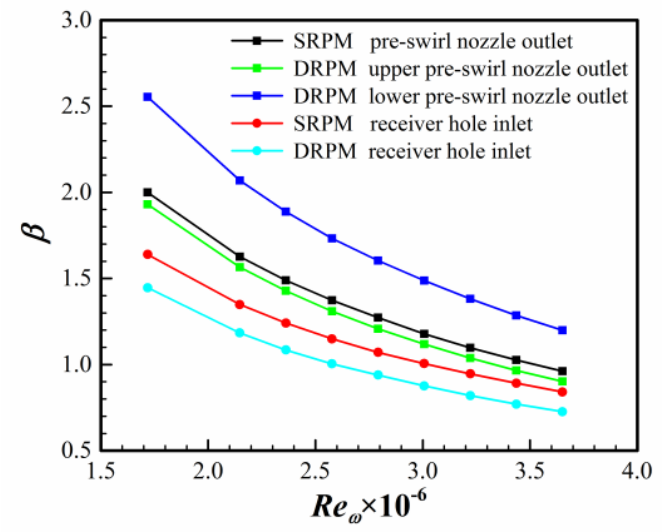

(a) Variation of $\beta$ at different locations with $R e_{\omega}$ $\left(P_{\text {in }}{ }^{*} / P_{\text {out }}=1.4\right)$

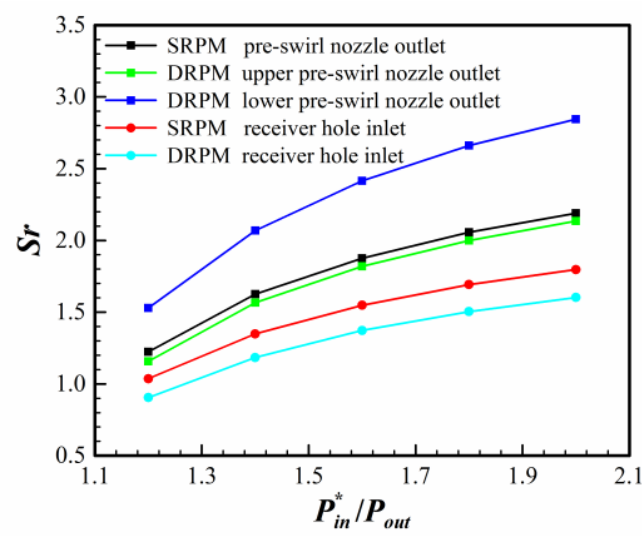

(b) Variation of $\beta$ at different locations with $P_{\text {in }}{ }^{*} / P_{\text {out }}\left(\operatorname{Re}_{\omega}=2.15 \times 10^{6}\right)$

Fig. 7. Variation of $\beta$ at different locations with $R e_{\omega}$ and $P_{\text {in }}{ }^{*} / P_{\text {out }}$ in SRPM and DRPM.

\subsection{Total Temperature Reduction Characteristics}

The total temperature reduction in the pre-swirl system is mainly affected by two factors: the static temperature reduction at the outlet of pre-swirl and dynamic temperature $\left(0.5 \rho V^{2}\right)$ at the receiver hole which related to the swirl ratio. The static temperature decreases after the expansion progress in the pre-swirl nozzle, tangential velocity component at the pre-swirl nozzle outlet reduces the relative tangential velocity of airflow in the downstream rotor-stator cavity, and thus reduces the relative total temperature at the receiver hole inlet. To observe the temperature reduction directly, Fig. 9 gives the variation of the total temperature reduction in relative frame with $R e_{\omega}$ and $P_{i n}{ }^{*} / P_{o u t}$, which is similar to Fig. 8 .

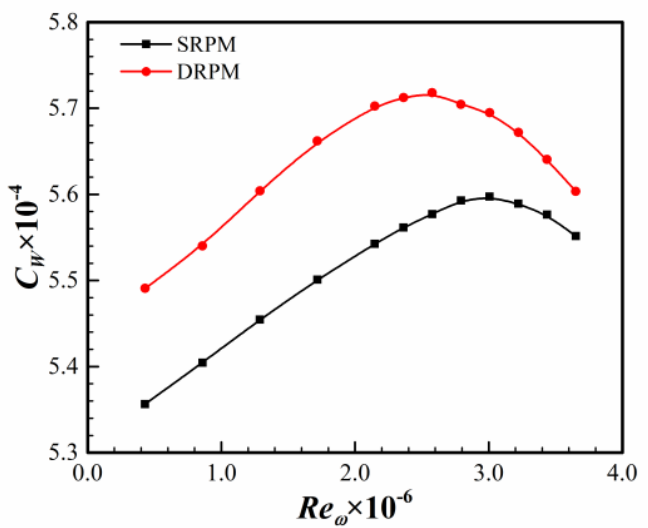

(a) Variation of $C_{W}$ with $\operatorname{Re}_{\omega}\left(P_{\text {in }}{ }^{*} / P_{\text {out }}=1.4\right)$

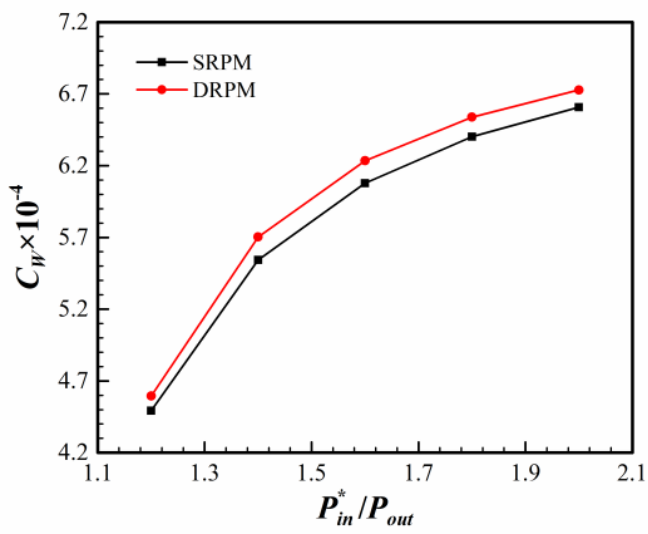

(b) Variation of $C_{W}$ with $P_{i n}{ }^{*} / P_{\text {out }}\left(R e_{\omega}=2.15 \times 10^{6}\right)$

Fig. 8. Variation of $C_{W}$ with $\operatorname{Re}_{\omega}$ and $P_{i n}{ }^{*} / P_{o u t}$ in SRPM and DRPM.

As the rotational Reynolds number increases, the swirl ratio at the inlet of the receiver hole gradually tends to 1 from a distance, when the swirl ratio is about 1 , the receiver hole has the minimum relative velocity, dynamic temperature, and relative total temperature then. When the rotational Reynolds number continues to increases, $\Delta T^{*}$ decreases because of the increase of friction temperature rise come from a faster wall. $\Delta T^{*}$ increases monotonically with the increase of pressure ratio, the increasing pressure ratio provides a more complete isentropic expansion progress in the preswirl nozzle, improves the velocity at the outlet of the pre-swirl nozzle and the static temperature reduction is more significant. On the other hand, the increasing pressure ratio leads to a much faster fluid than the rotor wall, and the flow "pushes" the rotational wall through viscous force. The work done by the flow on rotational disk reduces the temperature thus got a larger $\Delta T^{*}$. The flow comes from the lower radius pre-swirl nozzle in DRPM 
suffer a more significant temperature rise due to the friction and centrifugal force, thus $\Delta T^{*}$ in DRPM is smaller than that in SRPM. The $\Delta T^{*}$ difference between the two models increases with the increases of rotational Reynolds number and pressure ratio, about $37.8 \%$ when $R e_{\omega}=3.65 \times 10^{6}$ and $14.9 \%$ when $P_{\text {in }}{ }^{*} / P_{\text {out }}=2.0$.

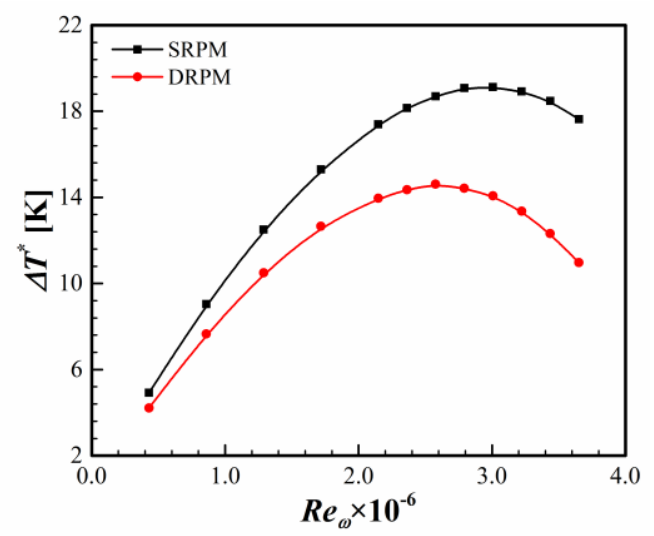

(a) Variation of $\Delta T^{*}$ with $\operatorname{Re}_{\omega}\left(P_{\text {in }}{ }^{*} / P_{\text {out }}=1.4\right)$

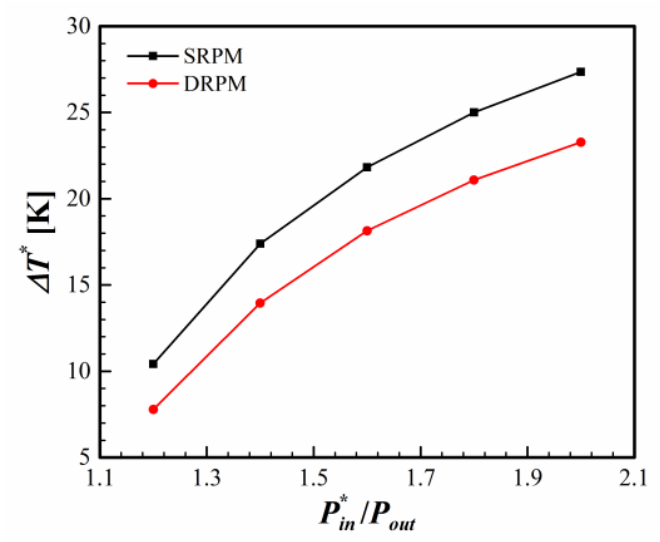

(b) Variation of $\Delta T^{*}$ with $P_{\text {in }}{ }^{*} / P_{\text {out }}\left(\operatorname{Re}_{\omega}=2.15 \times 10^{6}\right)$

Fig. 9. Variation of $\Delta T^{*}$ with $\operatorname{Re}_{\omega}$ and $P_{\text {in }}{ }^{*} / P_{\text {out }}$ in SRPM and DRPM.

\subsection{Comparison and Discussion of CFD and Theoretical Results}

Equations (12) and (13) gives the theoretical equations to calculate the total temperature reduction coefficient in two models with the ignorance of friction torque on stator disk. Fig. 10 presents the comparison of numerical results with theoretical analysis results. It can be found that they are in good agreement within the calculation conditions in this paper. However, the difference between CFD and theoretical results with the variation of rotational Reynolds number up to about $17.3 \%$ in SRPM and $5.7 \%$ in DRPM, $11.2 \%$ in SRPM and $-5.7 \%$ in DRPM with the variation of pressure ratio.

As discussed above, the theoretical equations make the assumption that the swirl ratio at receiver hole is equal to 1 , and the friction torque on the surface of the stator disk is ignored, however, in practice, the deviation of receiver hole swirl ratio from 1 is far, leading to a huge deviation in total temperature reduction coefficient, besides, the friction torque on the surface of stator disk is mainly influenced by rotational Reynolds number, angular velocity and average swirl ratio in the rotor-stator cavity (Denecke et al. 2005) and non-ignorable in high rotational Reynolds numbers. These two are the main cause of deviation between CFD and theoretical results.

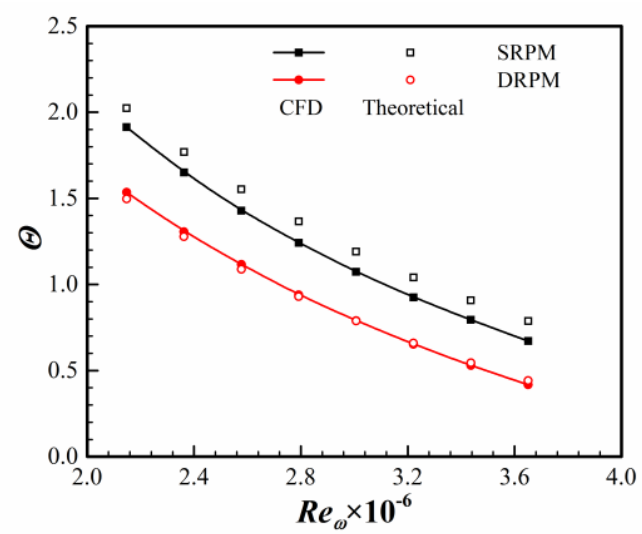

(a) Variation of $\Theta$ with $\operatorname{Re}_{\omega}\left(P_{\text {in }}{ }^{*} / P_{\text {out }}=1.4\right)$

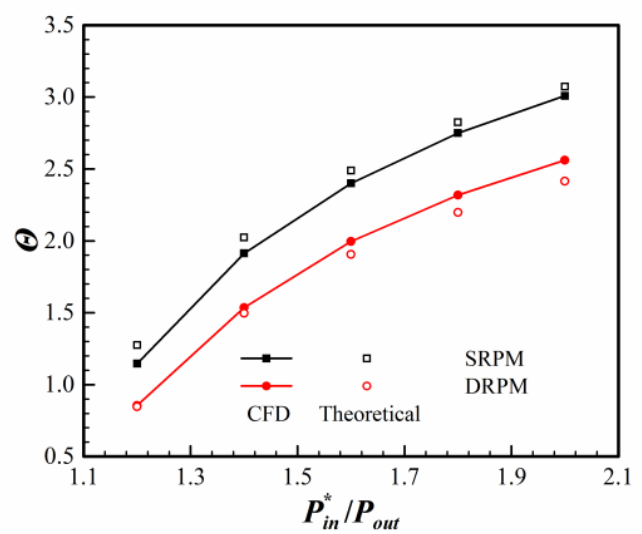

(b) Variation of $\Theta$ with $P_{\text {in }}{ }^{*} / P_{\text {out }}\left(R e_{\omega}=2.15 \times 10^{6}\right)$

Fig. 10. Comparison of the variation of $\Theta$ with $R e_{\omega}$ and $P_{i n}{ }^{*} / P_{o u t}$ in SRPM and DRPM.

\section{Conclusion}

Combined numerical simulation and theoretical analysis are used to research the DRPM and compared with traditional SRPM. Dimensionless mass flow rate and temperature reduction profiles with rotational Reynolds number and system pressure ratio are presented and compared. The main conclusions have been made as follows.

(1) Dimensionless mass flow rate and total temperature reduction in the pre-swirl system first increase and then decrease with the increase of rotational Reynolds number. Reaching the maximum value when the swirl ratio at the receiver hole is equal to 1 . The increase of pressure ratio promotes the airflow to do work on the rotor disk through viscous 
force and improves the total temperature reduction.

(2) Flow characteristic at the receiver hole is the key factor that influences mass flow and total temperature. Flow incidence angle is positive at a low rotational Reynolds number and decreases with the increase of rotational Reynolds number, the location of separation moves from the trailing edge wall to the leading edge wall of the receiver hole which means that the effective flow area of the receiver hole varies with rotational Reynolds number and reaches the maximum at zero flow incidence angle with swirl ratio equal to 1 .

(3) Lower radius pre-swirl nozzle flow can bring more significant pressure increase but higher temperature rise at the same time. DRPM can improve the dimensionless mass flow by $3.0 \%$ in the range of rotational Reynolds number and $2.8 \%$ in the range of pressure ratio compared with SRPM with constant total inlet area of pre-swirl nozzles. On the other hand, total temperature reduction in DRPM decreased by $37.8 \%$ in the range of rotational Reynolds number and $14.9 \%$ in the range of pressure ratio compared with SRPM due to the significant temperature rise in the progress of radial outward of lower pre-swirl nozzle

(4) The results obtained from simplified theoretical equations were, in the main, in good agreement with the CFD results. Temperature reduction in DRPM can reach a similar level of SRPM and result in a higher mass flow rate if the radial location of dual row pre-swirl nozzles and the mass flow distribution ratio are arranged appropriately. This paper is academic research with the numerical method. Based on the presented investigation, further experimental testing is planned.

\section{ACKNOWLEDGEMENTS}

The authors gratefully acknowledge the technical and financial supports from Shenyang Aeroengine Research Institute of Aero Engine Corporation of China.

\section{REFERENCES}

ANSYS, Inc. (2013).ANSYS CFX-Solver theory guide (release 15.0). ANSYS, Inc., Pennsylvania, USA.

Benim, A. C., M. Cagan, B. Bonhoff and D. Brillert (2005). Simulation of Flow in Gas Turbine Pre-Swirl Systems with Emphasis on RotorStator Interface Treatment. Proceedings of the 3rd IASME/WSEAS Int. Conf. on Fluid Dynamics \& Aerodynamics, Corfu, Greece, 206-211.

Bricaud, C., B. Richter, K. Dullenkopf and H. J. Bauer (2005). Stereo PIV measurements in an enclosed rotor-stator system with pre-swirled cooling air. Experiments in Fluids 39(2), 202212.

Chew, J. W., N. J. Hills, S. Khalatov, T. Scanlon and A. Turner (2003). Measurement and analysis of flow in a pre-swirled cooling air delivery system. Proceedings of ASME Turbo Expo collected with the international joint power generation conference, Atlanta, USA.

Ciampoli, F., J. Chew, S. Shahpar and E. Willocq (2007). Automatic optimization of preswirl nozzle design. Journal of Engineering for Gas Turbines and Power 129(2), 387-393.

Denecke, J., K. Dullenkopf, S. Wittig and H. J. Bauer (2005). Experimental investigation of the total temperature increase and swirl development in rotating labyrinth seals. Proceedings of ASME Turbo Expo 2005, RenoTahoe, USA.

Dittmann, M., T. Geis, V. Schramm, S. Kim and S. Wittig (2002). Discharge coefficients of a preswirl system in secondary air systems. Journal of Turbomachinery 124(1), 119-124.

Farzaneh-Gord, M., M. Wilson, J. M. Owen (2005). Numerical and theoretical study of flow and heat transfer in a pre-swirl rotor-stator system. Proceedings of ASME Turbo Expo 2005, Nevada, USA.

Javiya, U., J. Chew and N. Hills (2011). A comparative study of cascade vanes and drilled nozzle design for pre-swirl. Proceedings of ASME Turbo Expo 2011, Vancouver, Canada.

Karabay, H., M. Wilson and J. M. Owen (2001). Predictions of effect of swirl on flow and heat transfer in a rotating cavity. International Journal of Heat and Fluid Flow 22(2), 143155.

Karabay, H., R. Pilbrow, M. Wilson, and J. M. Owen (2000). Performance of pre-swirl rotating-disc systems. Journal of Engineering for Gas Turbines and Power 122(3), 442-450.

Lakshminarayana, B. (1995). Fluid dynamics and heat transfer of Turbomachinery. John Wiley and Sons, New York, USA

Lewis, P., M. Wilson, G. Lock and M. Owen (2009). Effect of radial location of nozzles on performance of pre-swirl systems. Journal of Power and Energy 223(2), 179-190.

Liao, G., X. Wang and J. Li (2014). Numerical investigation of the pre-swirl rotor-stator system of the first stage in gas turbine Applied Thermal Engineering 73, 940-952.

Liu Y. X., G. W. Liu, X. Z. Kong and Y. Wang (2018). Experimental testing and numerical analysis on the nozzle effects in preswirl system. Journal of Propulsion and Power 34(4), 1015-1025.

Liu, G. W., Y. X. Liu, X. Z. Kong and Q. Feng (2017). A new design of vane-shaped hole preswirl nozzle. Journal of Power and Energy 
Z. L. Xia et al. / JAFM, Vol. 13, No. 4, pp. 1299-1309, 2020.

231(1), 14-24.

Meierhofer, B. and C. J. Franklin (1981). An investigation of a preswirled cooling airflow to a turbine disc by measuring the air temperature in the rotating channels. Proceedings of ASME Turbo Expo, Houston, USA.

Popp, O., H. Zimmermann and J. Kutz (1998). CFD analysis of coverplate receiver flow. Journal of Turbomachinery 120(1), 43-49.

Sun, Z and J. Chew (2017). Study of a conceptual design for cooled cooling air in a preswirl cavity, 23rd ISABE Conference, Manchester, UK.

Wang, S.F., Q. H. Zhu, Y. Zhang, H. F. Luan and A. X. Huang (2007). Numerical studies of heat transfer in a rotor-stator cavity with different radial positions of pre-swirl inlet. Journal of
Aerospace Power 22(8), 1227-1232.

Wu, C., B. Vaisman and K. McCusker (2011). CFD analyses of HPT blade air delivery system with and without impellers. Proceedings of ASME Turbo Expo 2011, Vancouver, Canada.

Yan, Y., M. Gord, G. Lock, M. Wilson and M. Owen (2003). Fluid dynamics of a pre-swirl rotorstator system. Journal of Turbomachinery 125(4), 641-647.

Zhang, L., G. Liu, Z. Jiang and Z. Jiang (2013). Numerical simulations on the flow characteristics and temperature drop of an inlet-enlarged pre-swirl hole. Journal of Propulsion Technology 34(3), 390-396. 